\title{
Epidemiological Features of Clostridium difficile Colonizing the Intestine of Jordanian Infants
}

\author{
Eman N. Abu-Khader, ${ }^{1}$ Eman F. Badran, ${ }^{2}$ and Asem A. Shehabi ${ }^{1}$ \\ ${ }^{1}$ Department of Pathology-Microbiology and Forensic Medicine, The University of Jordan, School of Medicine, Amman, Jordan \\ ${ }^{2}$ Department of Pediatrics, Jordan University Hospital, Amman, Jordan \\ Correspondence should be addressed to Asem A. Shehabi; ashehabi@ju.edu.jo
}

Received 11 August 2017; Revised 11 November 2017; Accepted 28 November 2017; Published 20 December 2017

Academic Editor: Barbara H. Iglewski

Copyright $\odot 2017$ Eman N. Abu-Khader et al. This is an open access article distributed under the Creative Commons Attribution License, which permits unrestricted use, distribution, and reproduction in any medium, provided the original work is properly cited.

\begin{abstract}
Clostridium difficile is commonly found in the intestine of infants without causing any disease. This study investigated the most important epidemiological features of $C$. difficile strains colonizing intestine of Jordanian infants. A total of 287 fecal samples were collected from infants admitted to the Jordan University Hospital (JUH) over the period of 2015. Samples were cultured for $C$. difficile and their growth was identified using microbiological culture and PCR. The overall C. difficile colonization rate among hospitalized and nonhospitalized infants was 37/287 (12.9\%). Neonates were less colonized than other infants (8.7\% verses $19.5 \%)$. Colonization of the infants with C. difficile toxigenic strains (TcdA and TcdB) was observed in $54 \%$ of the isolates, whereas those colonized with nontoxigenic strains were $46 \%$ and only one isolate was positive for binary toxin. Breast feeding of infants is a significant factor associated with decreased colonization with C. difficile. All C. difficile strains were susceptible to vancomycin and metronidazole, while high resistance rate to ciprofloxacin (78.4\%) and less resistance rate to erythromycin (29.7\%) were detected among the isolates. The results showed that $40.5 \%$ of the isolates carried mutated gyrA and gyrB genes which have cross-resistance to ciprofloxacin and moxifloxacin. This study represents useful epidemiological features about $C$. difficile colonizing intestine of infants living in a developing country.
\end{abstract}

\section{Introduction}

Clostridium difficile is a major cause of nosocomial antibioticassociated diarrhea due to the production of toxins $\mathrm{A}$ and $\mathrm{B}$. C. difficile infection (CDI) can result in asymptomatic carriage, mild diarrhea, or pseudomembranous colitis (PMC). CDI can be associated with significant morbidity, mortality, and healthcare costs in hospitalized patients $[1,2]$. Increased incidence of CDI is coupled with more serious clinical presentation; especially mortality among patients ranges from 24 to $50 \%$ [3-5].

The rate of $C$. difficile colonization among newborns varies widely (2.5-90\%) [1], mainly during the first 2 years of life and usually in an asymptomatic manner $[6,7]$. A recent study from USA reported increased rate of pediatric CDIrelated hospitalization over the period 1997-2006 [8]. Several hypotheses have been reported to explain asymptomatic state of $C$. difficile in newborns. These include the competitive intestinal colonization by nontoxigenic strains, the immaturity of the immune system, possible absence of toxin receptors in the intestinal tract, modulation of toxin production by the infant microbiota, and toxin neutralization by maternal antibodies $[6,9]$.

Transmission of $C$. difficile occurs primarily in healthcare facilities, where exposure to antimicrobial drugs and environmental contamination by its spores are causing mostly nosocomial infection $[10,11]$.

This study investigated the occurrence rate of $C$. difficile intestinal colonization and most important epidemiological factors associated with its presence in intestine of Jordanian infants.

\section{Patients and Methods}

2.1. Study Population. This prospective convenience sampling study was conducted at the Pediatric Department/Jordan 
TABLE 1: Demographic characteristics of 287 infants with positive and negative C. difficile culture.

\begin{tabular}{|c|c|c|c|}
\hline Variables & Number (\%) of positive C. difficile & Number (\%) of negative C. difficile & $P$ value \\
\hline \multicolumn{4}{|l|}{ Age by group } \\
\hline 1 day $-\leq 30$ days & $15(8.7)$ & $157(91.3)$ & \multirow{2}{*}{0.050} \\
\hline$>1$ month $-\leq 1$ year & $22(19.5)$ & $93(80.5)$ & \\
\hline \multicolumn{4}{|l|}{ Gender } \\
\hline Male & $18(11.9)$ & $133(88.1)$ & \multirow{2}{*}{0.605} \\
\hline Female & $19(14.0)$ & $117(86.0)$ & \\
\hline \multicolumn{4}{|l|}{ Hospital ward } \\
\hline NICU* & $0(0.0)$ & $50(100)$ & \multirow{2}{*}{0.001} \\
\hline OPD & $37(15.6)$ & $200(84.4)$ & \\
\hline \multicolumn{4}{|l|}{ Antibiotics treatment } \\
\hline Yes & $10(10.5)$ & $85(89.5)$ & \multirow{2}{*}{0.400} \\
\hline No & $27(14.1)$ & $165(85.9)$ & \\
\hline \multicolumn{4}{|l|}{ Presence of diarrhea ${ }^{* *}$} \\
\hline Yes & $3(23.1)$ & $10(76.9)$ & \multirow{2}{*}{0.262} \\
\hline No & $34(12.4)$ & $240(87.6)$ & \\
\hline \multicolumn{4}{|l|}{ Hospital length of stay } \\
\hline $1-7$ days & $14(14.1)$ & $85(85.9)$ & \multirow{3}{*}{0.062} \\
\hline 8-30 days & $1(2.0)$ & $49(98.0)$ & \\
\hline$>30$ days & $2(15.4)$ & $11(84.6)$ & \\
\hline \multicolumn{4}{|l|}{ Gestational age } \\
\hline$<32$ & $0(0.0)$ & $12(100)$ & \multirow{4}{*}{0.420} \\
\hline $32-36$ & $9(14.3)$ & $54(85.7)$ & \\
\hline $37-39$ & $16(11.6)$ & $122(88.4)$ & \\
\hline$>39$ & $12(16.2)$ & $62(83.8)$ & \\
\hline \multicolumn{4}{|l|}{ Birth weight } \\
\hline$\leq 2500$ & $16(16.2)$ & $83(83.8)$ & \multirow{2}{*}{0.230} \\
\hline$>2500$ & $21(11.2)$ & $167(88.8)$ & \\
\hline \multicolumn{4}{|l|}{ Mode of delivery } \\
\hline Normal vaginal delivery & $20(13.8)$ & $125(86.2)$ & \multirow{2}{*}{0.654} \\
\hline Cesarean section & $17(12.0)$ & $125(88.0)$ & \\
\hline \multicolumn{4}{|l|}{ Type of feeding } \\
\hline Breast & $4(5.1)$ & $74(94.9)$ & \multirow{2}{*}{0.012} \\
\hline Formula and mix & $33(15.8)$ & $176(84.2)$ & \\
\hline
\end{tabular}

${ }^{*}$ Included 50 newborns which were admitted to neonatal intensive care unit (NICU). ${ }^{* *}$ Mostly soft stools without any clinically significant gastrointestinal symptoms or diarrhea during the collection of the specimens.

University Hospital (JUH) over a period of 8 months from March 2015 through October 2015. The study was approved by the School of Medicine and the School of Graduate studies at The University of Jordan. A total of 287 stool fecal samples were obtained from 151-male and 136-female infants aged one year or less.

Biographical and clinical data which were obtained from each infant included age, gender, name, duration of hospitalization, presence of diarrhea, hospital length of stay, mode of delivery, type of feeding, and antibiotics treatment at the time of sampling (Table 1).

2.2. Ethical Permission. A permission was also obtained from the Ethical Review Board (ERB) at the Jordan University Hospital (JUH), permission number 75/2015. Verbal consent was obtained from all mothers of infants after explaining the aim of the study.

2.3. Culture and Identification of C. difficile. One fecal sample from each patient was collected during investigation in outpatients' clinic or directly after admission to hospital, using sterile prewetted cotton swabs in $0.85 \%$ normal saline. All fecal specimens were sent within 2-3 hrs to research microbiology labs. The specimens were first treated by absolute ethanol (v/v) for $1 \mathrm{~h}$ before inoculation into Clostridium difficile moxalactam-norfloxacin agar plates (CDMN, Oxoid, England) which was supplemented with $7 \%$ (v/v) defibrinated horse blood. Culture plates were incubated for 48 hours at $37^{\circ} \mathrm{C}$ under anaerobic condition, and a control reference strain of C. difficile (NCTC 11204) was included. All suspected 
colonies resemble C. difficile in their appearance which were used for Gram and spore stains and later confirmed by Remel RapID ANA II system (Remel Inc., Lenexa, KS, USA). All C. difficile isolates were frozen at $-70^{\circ} \mathrm{C}$ in brain-heart infusion broth (BHIB) with $20 \%$ glycerol for further antimicrobial susceptibility test and characterization of their potential toxins genes.

2.4. Antimicrobial Susceptibility Testing. All C. difficile isolates were tested using $E$-tests (Oxoid, England) for vancomycin, metronidazole, ciprofloxacin, and erythromycin according to guidelines of CLSI (2015) [12]. A quality control C. difficile strain (NCTC 11204) was included.

2.5. Molecular Methods. C. difficile DNA was prepared using a single colony by boiling at $95^{\circ} \mathrm{C}$ for $10 \mathrm{~min}$ in water bath. The identity of $C$. difficile isolates was confirmed by amplification of the $16 \mathrm{~S}$ rRNA gene using $C$. difficile specific primers (PG48 and B) [13]. PCR reactions were used for the detection of $C$. difficile toxin genes $\mathrm{A}$ and $\mathrm{B}(T c d A$ and $T c d B)$ and to detect genes encoding the enzymatic $(c d t A)$ and binding $(c d t B)$ components of the binary toxin as described by Terhes et al. [14]. Mutation detection in $g y r A$ and gyrB genes was carried out using PCR as reported by Dridi et al. [15].

2.6. Statistics. All data analyses were carried out using SPSS version 20. $\chi^{2}$-test was used for statistical analysis. $P \leq 0.05$ was considered statistically significant.

\section{Results}

3.1. Characteristics of Infants. Table 1 shows important characters from all examined infants with positive or negative $C$. difficile fecal isolates according to their age group, admission to intensive care unit (INCU) or outpatients department (OPD), sex, diarrhea, duration of hospitalization, type of feeding, birth weight (BWT), mode of delivery, and current antibiotic treatment.

3.2. Detection of C. difficile. A total of $37 / 287$ (12.9\%) of $C$. difficile isolates were recovered from infants aged $\leq 1$ year, of these 20/37 (54.1\%) were toxigenic strains. All isolates were confirmed using 16S rRNA gene-targeted PCR.

3.3. Detection of C. difficile Toxigenic Genes. Table 2 shows that $13 / 37(35.1 \%)$ carried both genes of toxin $\mathrm{A}(\mathrm{Tcd} A)$ and $\mathrm{B}(\mathrm{Tcd} B)$, whereas $17 / 37$ (45.9\%) of isolates were negative for toxin A and B genes. Only one isolate (2.7\%) was positive for binary toxin genes ( $T c d A$ and $T c d B$ ) (Table 2). Successful sequencing (99\%) of the $c d t A$ and $c d t b$ genes was used to confirm the identity of one isolate that was positive for the binary toxin genes (Macrogen, Korea). The sequence reads were aligned manually using the online software NCBI BLAST.

3.4. Antimicrobial Susceptibility. All C. difficile isolates were $100 \%$ susceptible for both vancomycin and metronidazole as shown by their MICs breakpoint, whereas the MICs for
TABLE 2: Toxigenic profile of 37 C. difficile isolates.

\begin{tabular}{lc}
\hline Toxin profile & Number of isolates (\%) \\
\hline A+ B+ & $13(35.2)^{*}$ \\
A+ B- & $1(2.7)$ \\
A- B+ & $6(16.2)$ \\
Negative A \& B & $17(45.9)^{* *}$ \\
\hline Total (\%) & $37(100)^{* * *}$ \\
\hline
\end{tabular}

* Only one isolate was positive for binary toxin genes as confirmed by sequencing; ${ }^{* *} 54.1 \%$ of the $C$. difficile isolates were toxigenic strains; *** 37/287 (12.9\%) were intestine colonized with C. difficile.

ciprofloxacin and erythromycin showed that 29/37 (78.4\%) and $11 / 37(29.7 \%)$ of the isolates were resistant, respectively. Fluoroquinolone resistance-determining mutated gene (gyrA and $g y r B$ ) were present in $15 / 37(40.5 \%)$ among the isolates (Table 3).

\section{Discussion}

This study demonstrates relatively low colonization rate of $C$. difficile (12.9\%) in stools of hospitalized and nonhospitalized infants aged $\leq 1$ year. Toxigenic C. difficile accounted for $54.1 \%$ of the isolates (Tables 1 and 2). A prospective study performed in France over 18-month period has found that the C. difficile colonization of French infants aged between 0 to 2 years was $33.7 \%$, and the colonization rate by a toxigenic strain was $7.1 \%$ which is slightly less than that in our study [9]. A recent study from USA reported that the rate of pediatric CDIrelated hospitalizations increased from 7.2 to $12.8 \%$ from 1997 to 2006; the lowest rate was observed in newborns $(0.5 \%)$, while incidence for children aged $<1$ year and those aged 5-9 years were $32 \%$ [8]. A study in Japan reported that the carriage rate of toxigenic $C$. difficile in neonates was very low $(2.5 \%)$ but was increased to $84.4 \%$ in infants under 2 years of age [16].

The reason why the incidence rates of $C$. difficile among infants differ widely between countries remains questionable. However, the rate of colonization in infants may be due to the low capacity of the infant gut flora to suppress growth of $C$. difficile or due to the absence of toxin receptors in the infantile gut mucosa [17]. Additionally, infants are more frequently colonized than adults, but they rarely develop $C$. difficile disease during the first year of their life [18-20].

The present study shows that infants receiving formula mixed milk were significantly more associated $(P<0.012)$ with $C$. difficile colonization than breast milk (Table 1). This finding was similar to other recent studies $[6,7,19]$. Otherwise, this study showed that there was no significant correlation $(P>0.05)$ between $C$. difficile colonization and certain neonatal conditions related to gender, gestational age, birth weight, mode of delivery, hospital length of stay, presence of soft stools, and antibiotic treatment.

In Jordan, most previous studies on C. difficile infection and colonization have involved mostly adult patients. A study performed at the Jordan University Hospital in 2007 found $13.7 \%$ prevalence rate of toxigenic $C$. difficile isolates among adult hospitalized patients as proved by the presence of positive culture/toxin genes or both and in association 
TABle 3: Antimicrobial MIC results of 37 C. difficile isolates.

\begin{tabular}{lccccc}
\hline Antimicrobial agents & MIC50 $(\mu \mathrm{g} / \mathrm{ml})$ & MIC90 $(\mu \mathrm{g} / \mathrm{ml})$ & Resistance breakpoint $(\mu \mathrm{g} / \mathrm{ml})$ & MIC $(\mu \mathrm{g} / \mathrm{ml})$ range & Number $(\%)$ of resistance \\
\hline Ciprofloxacin & 5.3 & 9.6 & 8 & $3.0-16.0$ & $29(78.4)$ \\
Erythromycin & 0.42 & 0.75 & 8 & $0.25-2.0$ & 1.0 \\
Vancomycin & 0.89 & 1.60 & 32 & $1.0-4.0$ & Null \\
Metronidazole & 0.09 & 0.16 & 32 & $0.023-0.25$ & Null \\
\hline
\end{tabular}

${ }^{*}$ A total of $40.5 \%$ of isolates were positive for both mutated GyrA and GyrB genes.

with diarrhea, but there was no single case found among children [21]. The current study indicates that there was no correlation between positive colonization of toxigenic C. difficile in infants and presence of soft stools, previous antibiotic treatment, or inflammatory bowel disease, and overall our findings were similar to that of other investigators $[18,19]$. A recent multicenter study done in three different private Jordanian hospitals in Amman over a period of 8 months showed high prevalence rate $(92.4 \%)$ of positive $C$. difficile toxins among adults as well as older patients with a prolonged hospital stay and comorbidities [22]. Additionally, a recent study indicated that infants are widely colonized by nontoxigenic $C$. difficile strains and their early intestinal colonization with toxigenic strains originated from adults [9].

This study shows that all 37 C. difficile isolates were susceptible to vancomycin and metronidazole and were highly resistant to ciprofloxacin $(78.4 \%)$ and moderate resistant to erythromycin (29.7\%) (Table 3). These results are similar to some extent to a previous study published from our hospital [21] which showed that all C. difficile isolates were highly susceptible to vancomycin and metronidazole, while moderate resistant rate was found to ciprofloxacin. These findings are also much related to those of other European studies $[15,23,24]$. It is also important to mention here that fecal E. coli isolates from Jordan infant and adults were highly resistant to ciprofloxacin, and it is well known that Jordan physicians are extensively using fluoroquinolones in treatment of urinary and respiratory tract infections [25-27].

In conclusion, this study presents important epidemiological data about occurrence of toxigenix $C$. difficile in intestines of hospitalized and nonhospitalized infants living in a Middle East country.

\section{Conflicts of Interest}

The authors declare that there are no conflicts of interest regarding the publication of this paper.

\section{Acknowledgments}

This study has been financially supported by the Dean of Research, The Jordan University, and by the Jordanian Research Fund, Amman, Jordan. The authors are thankful for the support of the Jordan University Hospital in Amman.

\section{References}

[1] E. Borali, G. Ortisi, C. Moretti et al., "Community-acquired Clostridium difficile infection in children: A retrospective study," Digestive and Liver Disease, vol. 47, no. 10, pp. 842-846, 2015.

[2] E. R. Dubberke, A. M. Butler, K. A. Reske et al., "Attributable outcomes of endemic Clostridium difficile-associated disease in nonsurgical patients," Emerging Infectious Diseases, vol. 14, no. 7, pp. 1031-1038, 2008.

[3] M. Bassetti, G. Villa, D. Pecori, A. Arzese, and M. Wilcox, "Epidemiology, diagnosis and treatment of Clostridium difficile infection," Expert Review of Anti-infective Therapy, vol. 10, no. 12, pp. 1405-1423, 2012.

[4] V. Wilson, L. Cheek, G. Satta et al., "Predictors of Death after Clostridium difficile Infection: A Report on 128 StrainTyped Cases from a Teaching Hospital in the United Kingdom," Clinical Infectious Diseases, vol. 50, no. 12, pp. e77-e81, 2010.

[5] V. G. Loo, P. L. Miller, M. A. Oughton et al., "A predominantly clonal multi-institutional outbreak of Clostridium difficileassociated diarrhea with high morbidity and mortality," The New England Journal of Medicine, vol. 353, pp. 2442-2449, 2005.

[6] C. Rousseau, I. Poilane, L. De Pontual, A.-C. Maherault, A. Le Monnier, and A. Collignon, "Clostridium difficile carriage in healthy infants in the community: A potential reservoir for pathogenic strains," Clinical Infectious Diseases, vol. 55, no. 9, pp. 1209-1215, 2012.

[7] S. Jangi and J. T. Lamont, "Asymptomatic colonization by clostridium difficile in infants: Implications for disease in later life," Journal of Pediatric Gastroenterology and Nutrition, vol. 51, no. 1, pp. 2-7, 2010.

[8] M. D. Zilberberg, G. S. Tillotson, and L. C. McDonald, "Clostridium difficile infections among hospitalized children, United States, 1997-2006," Emerging Infectious Diseases, vol. 16, no. 4, pp. 604-609, 2010.

[9] C. Rousseau, F. Levenez, C. Fouqueray, J. Doré, A. Collignon, and P. Lepage, "Clostridium difficile colonization in early infancy is accompanied by changes in intestinal microbiota composition," Journal of Clinical Microbiology, vol. 49, no. 3, pp. 858-865, 2011.

[10] L. C. McDonald, G. E. Killgore, A. Thompson et al., "An epidemic, toxin gene-variant strain of Clostridium difficile," The New England Journal of Medicine, vol. 353, no. 23, pp. 2433-2441, 2005.

[11] M. Ogielska, P. Lanotte, C. Le Brun et al., "Emergence of community-acquired Clostridium difficile infection: The experience of a French hospital and review of the literature," International Journal of Infectious Diseases, vol. 37, pp. 36-41, 2015.

[12] Clinical Laboratory and Standards Institute Methods for Dilution Antimicrobial Susceptibility Tests for Bacteria That Grow Anaerobically, CLSI, Villanova, PA, USA, 2015.

[13] C. Gonçalves, D. Decré, F. Barbut, B. Burghoffer, and J.-C. Petit, "Prevalence and characterization of a binary toxin (actinspecific ADP-ribosyltransferase) from Clostridium difficile," 
Journal of Clinical Microbiology, vol. 42, no. 5, pp. 1933-1939, 2004.

[14] G. Terhes, E. Urbán, J. Sóki, K. A. Hamid, and E. Nagy, "Community-acquired Clostridium difficile diarrhea caused by binary toxin, toxin $\mathrm{A}$, and toxin $\mathrm{B}$ gene-positive isolates in Hungary," Journal of Clinical Microbiology, vol. 42, no. 9, pp. 4316-4318, 2004.

[15] L. Dridi, J. Tankovic, B. Burghoffer, F. Barbut, and J.-C. Petit, "gyrA and gyrB mutations are implicated in cross-resistance to ciprofloxacin and moxifloxacin in Clostridium difficile," Antimicrobial Agents and Chemotherapy, vol. 46, no. 11, pp. 3418-3421, 2002.

[16] S. O. Matsuki, E. Shozu, M. Inoue et al., "Colonization by Clostridium difficile of neonates in a hospital, and infants and children in three day-care facilities of Kanazawa, Japan," International Microbiology, vol. 8, no. 1, pp. 43-48, 2005.

[17] L. V. McFarland, S. A. Brandmarker, and S. Guandalini, "Pediatric Clostridium difficile: A phantom menace or clinical reality?" Journal of Pediatric Gastroenterology and Nutrition, vol. 31, no. 3, pp. 220-231, 2000.

[18] I. Adlerberth, H. Huang, E. Lindberg et al., "Toxin-Producing clostridium difficile strains as long-term gut colonizers in healthy infants," Journal of Clinical Microbiology, vol. 52, no. 1, pp. 173-179, 2014.

[19] M. R. Nicholson, I. P. Thomsen, and K. M. Edwards, "Controversies Surrounding Clostridium difficile Infection in Infants and Young Children," Children, vol. 1, no. 1, pp. 40-47, 2014.

[20] M. D. Redelings, F. Sorvillo, and L. Mascola, "Increase in Clostridium difficile-related mortality rates, United States, 1999-2004," Emerging Infectious Diseases, vol. 13, no. 9, pp. 14171419, 2007.

[21] L. M. Nasereddin, F. G. Bakri, and A. A. Shehabi, "Clostridium difficile infections among Jordanian adult hospitalized patients," American Journal of Infection Control, vol. 37, no. 10, pp. 864866, 2009.

[22] J. Wadi, A. S. Ayesh, L. A. Shanab et al., "Prevalence of Clostridium difficile infections among hospitalized patients in Amman, Jordan: A multi-center study," International Arabic Journal of Antimicrobial Agents, vol. 5, no. 1, 2015.

[23] O. Aspevall, A. Lundberg, L. G. Burman, T. Åkerlund, and B. Svenungsson, "Antimicrobial susceptibility pattern of Clostridium difficile and its relation to PCR ribotypes in a Swedish University Hospital," Antimicrobial Agents and Chemotherapy, vol. 50, no. 5, pp. 1890-1892, 2006.

[24] A. A. Shehabi, E. F. Badran, and E. N. Abu-Khader, "Clostridium difficile: infection, diagnosis and treatment with antimicrobial drugs: a review article," The International Arabic Journal of Antimicrobial Agents, vol. 5, no. 4:1, pp. 1-13, 2015.

[25] E. F. Badran, R. A. Qamer Din, and A. A. Shehabi, "Low intestinal colonization of Escherichia coli clone ST131 producing CTX-M-15 in Jordanian infants," Journal of Medical Microbiology, vol. 65, no. 2, Article ID 000210, pp. 137-141, 2016.

[26] A. M. Abu Salah, F. E. Badran, and A. A. Shehabi, "High incidence of multidrug resistant Escherichia coli producing CTXM-type ESBLs colonizing the intestine of Jordanian infants," International Arabic Journal of Antimicrobial Agents, vol. 3, no. 4:3, pp. 1-8, 2013.

[27] M. R. Abu Sneineh, A. Mahafzah, N. Abdallat, and A. A. Shehabi, "High incidence of multidrug-resistant fecal E. coli producing ESBLs and carried ST131 in Jordanian adults," International Arabic Journal of Antimicrobial Agents, vol. 7, no. 2, pp. $1-8,2017$. 

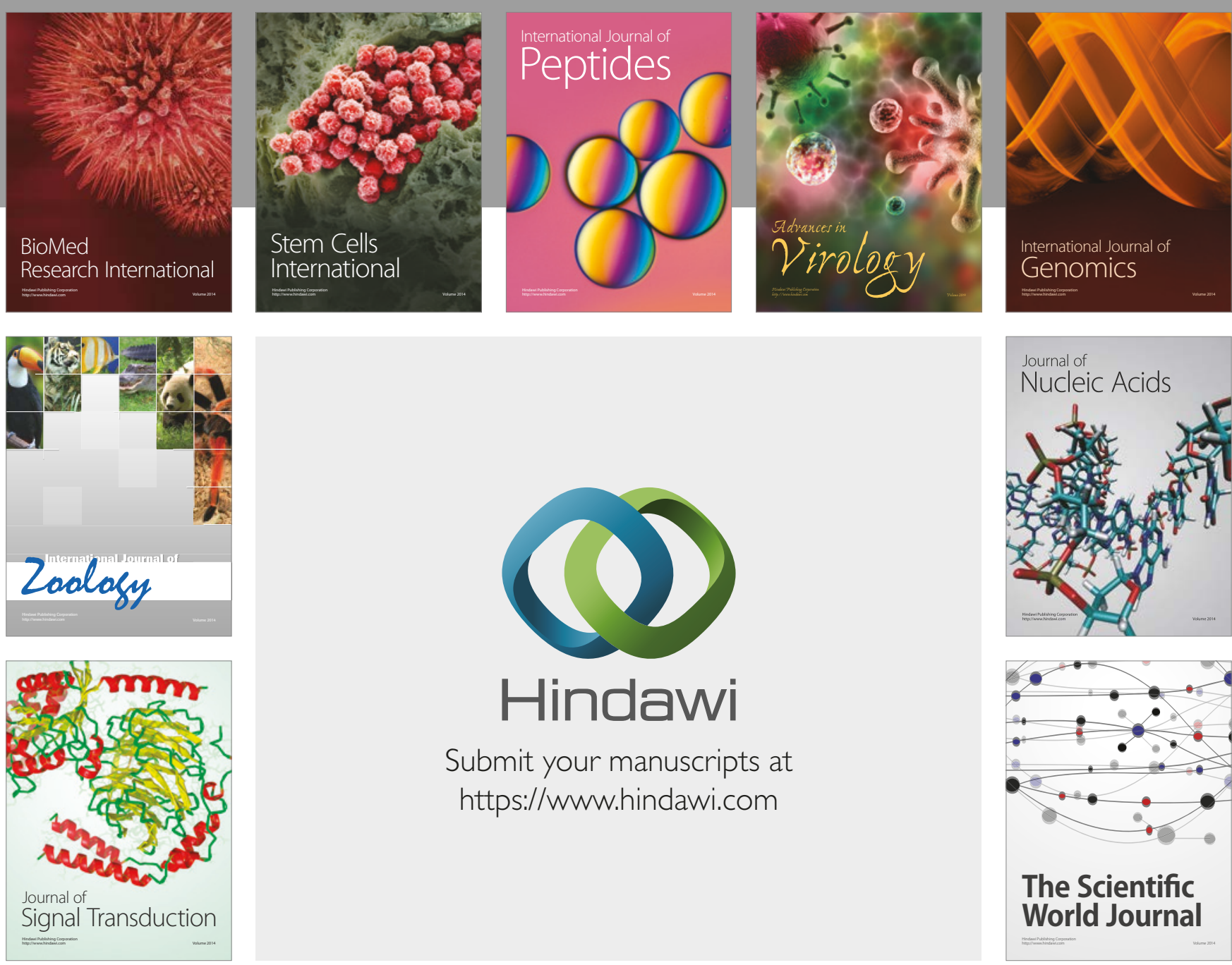

Submit your manuscripts at

https://www.hindawi.com
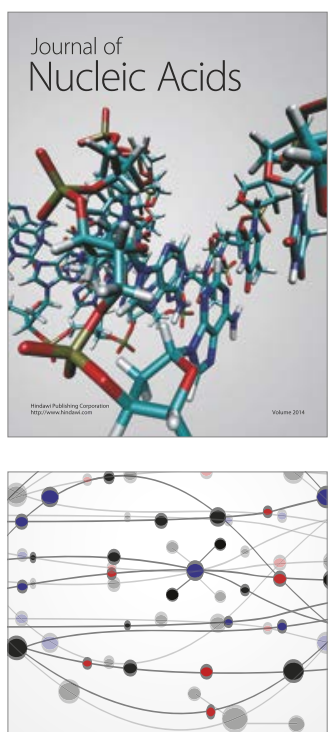

The Scientific World Journal

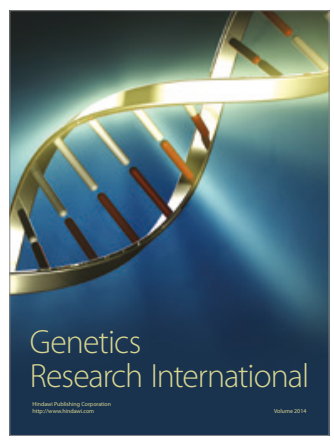

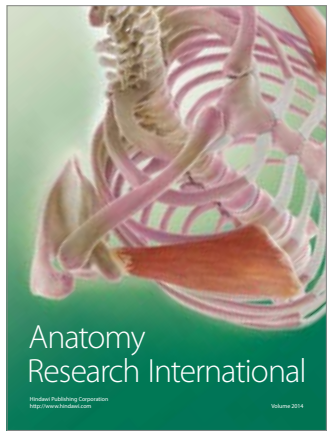

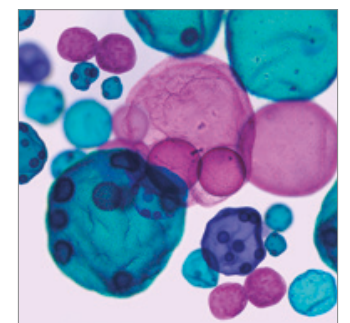

International Journal of Microbiology
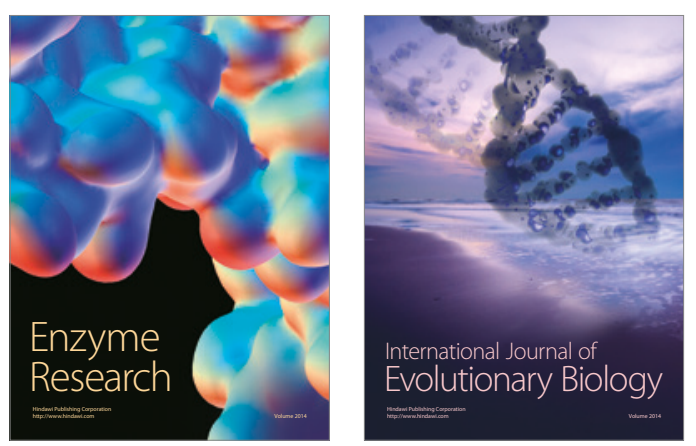
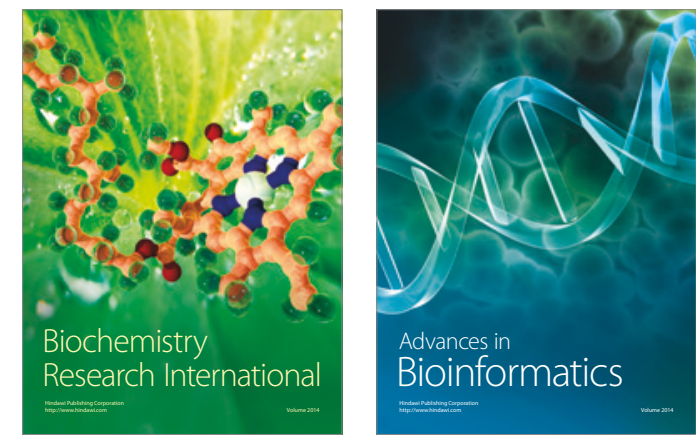

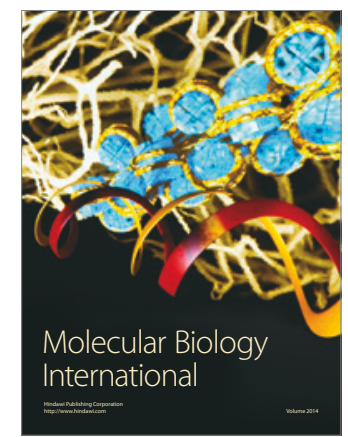

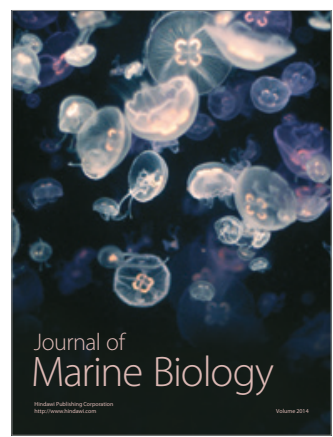

